\title{
Up-regulation of miR-224 promotes cancer cell proliferation and invasion and predicts relapse of colorectal cancer
}

Guang-jun Zhang ${ }^{1,2+}$, He Zhou $^{1,2+}$, Hua-Xu Xiao ${ }^{3}$, Yu Li ${ }^{4}$ and Tong Zhou ${ }^{1,2^{*}}$

\begin{abstract}
Background: MicroRNAs (miRNAs) are small, non-coding RNAs that can function as oncogenes or tumor suppressors in human cancer. Abnormally expressed miR-224 was found to play a fundamental role in several types of cancer. The aim of this study was to investigate the prognostic and biological values of miR-224 in colorectal cancer (CRC).

Methods: Quantitative RT-PCR (qRT-PCR) was used to evaluate expression levels of miR-224. The postoperative survival rate was analyzed with Kaplan-Meier method. The roles of miR-224 in cell proliferation, migration and invasion were analyzed with pre-miR-224 transfected cells. In addition, the regulation of SMAD4 by miR-224 was evaluated by qRT-PCR, Western blotting and luciferase reporter assays.

Results: In the present study, we demonstrated that miR-224 was significantly up-regulated in CRC tissue samples and associated with disease relapse and a relative poorer disease-free survival rate. Moreover, ectopic expression of miR-224 potently promoted tumor cell proliferation, migration and invasion in vitro. Furthermore, the overexpression of miR-224 in CRC cell lines decreased SMAD4 expression at the translational level and decreased SMAD4-driven luciferase-reporter activity.
\end{abstract}

Conclusions: Our data suggest that miR-224 could play an oncogenic role in the cellular processes of CRC and represent a novel biomarker for tumor relapse of CRC patients.

Keywords: Colorectal cancer, miR-224, SMAD4, Invasion, Relapse

\section{Introduction}

Colorectal carcinoma (CRC) is one of the most common cancers, and is a significant contributor to cancer death [1]. Although surgery currently offers the possibility of prolonged survival for CRC patients, a significant number of patients with CRC who undergo curative surgery develop local recurrence or distant metastasis, leading to shorter survival [2]. A better understanding of the molecular mechanisms underlying tumor recurrence or metastasis is essential to facilitate the prevention and treatment of advanced CRC.

\footnotetext{
*Correspondence: zhoutong0088@163.com

${ }^{\dagger}$ Equal contributors

'The First Department of General Surgery, The Affiliated Hospital of North Sichuan Medical College, Nanchong, Sichuan, People's Republic of China ${ }^{2}$ Institute of Hepatobiliary, Pancreas and Intestinal Disease, North Sichuan Medical College, Nanchong, Sichuan, People's Republic of China Full list of author information is available at the end of the article
}

MicroRNAs (miRNAs) are endogenous non-coding RNAs that negatively regulate target gene expressions by binding to 3 '-untranslated region (UTR) [3,4]. MiRNAs participate in gene regulation, apoptosis, hematopoietic development, the maintenance of cell differentiation, and tumor genesis $[5,6]$. The dysregulation of miRNAs is common in various carcinomas and plays an important role in tumorigenesis, tumor progression, metastasis and relapse in cancers [7-9].

Recently, miR-224 has been shown to be up-regulated in cervical cancer and pancreatic ductal adenocarcinomas $[10,11]$, and the involvement of miR-224 in the tumorigenesis and development of breast cancer and hepatocellular carcinoma has also been reported $[12,13]$. Previous reports revealed that miR-224 was upregulated in CRC by miRNA microarray analysis $[14,15]$. Moreover, miR-224 is one of the most highly differentially

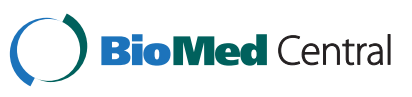


expressed miRNAs in methotrexate-resistant cells, and its over-expression induces the resistant phenotype in HT29 colon cancer cells [16]. Taken together, these studies suggest that miR-224 functions as an oncogenic miRNA. However, the association between miR-224 and relapse of colorectal cancer has not been evaluated yet, and the biological roles of miR-224 in CRC remain poorly understood.

Thus, we investigated the relationship between expression level of miR-224 and prognosis in CRC, and further studied the possible function of miR-224 in the CRC cell line. Our study results showed the high expression level of miR-244 in CRC was significantly associated with a relative poorer disease-free survival rate. Moreover, we also demonstrated miR-224 promoted proliferation, migration and invasion of SW480 cells, at least partially through suppression of SMAD4 expression.

\section{Materials and methods}

\section{Patients and tissue samples}

A total of 108 stage I-II (UICC, 6th ed., 2002) colorectal patients received radical surgery at the First Department of General Surgery, the Affiliated Hospital of North Sichuan Medical College, from January 2004 to January 2009, were collected. All clinicopathological characteristics of patients with disease relapse $(n=40)$ or without disease relapse $(n=68)$ within 3 years after surgery were available for all patients. Disease relapse was defined as local recurrence or distant metastasis of colorectal cancer. All tissue specimens were derived from 108 patients who did not received neoadjuvant therapy before surgery. The patients who received postoperative adjuvant therapy were also excluded. To test whether miR-224 was differentially expressed between paired tumor and adjacent normal tissue in the same subject, we recruited a second cohort comprising 20 CRC patients. All tissue samples were immediately frozen in liquid nitrogen and stored at $-80^{\circ} \mathrm{C}$ for subsequent analysis. The median follow-up time was 48.3 months (12.6-62.5 months) until June, 2012. Disease-free survival (DFS) was calculated from radical surgery to the first disease relapse. Informed written consent was obtained from each patient, and research protocols were approved by the Medical Ethics Committee of North Sichuan Medical College.

\section{Cell culture}

The human CRC cell line SW480 was purchase from American Type Culture Collection. The cells were maintained in Dulbecco's modified Eagle's medium supplemented with $10 \%$ fetal bovine serum, $100 \mathrm{u} / \mathrm{ml}$ penicillin and $100 \mathrm{mg} / \mathrm{ml}$ streptomycin, at $37^{\circ} \mathrm{C}$ in a humidified atmosphere of $5 \% \mathrm{CO}_{2}$.

\section{RNA extraction and real-time RT-PCR}

Total RNA was extracted using TRIzol reagent (Invitrogen, Carlsbad, CA, USA). The PCR primers for miR-224 and U6 were purchased from Applied Biosystems (Applied Biosystems, Foster City, CA, USA). The PCR primers for SMAD4 were 5'-TGGCCCAGGATC AGT AGGT-3' and 5' ${ }^{\prime}$-CATCAACACCAATTCCAGCA-3'. The primers for $\beta$-actin: 5 '-CCAAGGCCAACCGCGA GAAGATGAC-3' and 5'-AGGGTACAT GGTGGTGC CGCCAGAC-3'. The first-strand cDNA was synthesized using the PrimeScript RT reagent Kit (TaKaRa, Dalian, China). Real-time PCR was performed using SYBR Premix Ex Taq (TaKaRa) and measured in a LightCycler 480 system (Roche, Basel, Switzerland). U6 or $\beta$-actin was used as internal control. Relative gene expression was calculated using $2^{-\Delta \mathrm{CT}}$ method, and fold change of gene was calculated using the equation $2^{-\Delta \Delta C T}$.

\section{Transfection of miRNA}

Ectopic expression of miR-244 in cells was achieved by transfection with Pre-miR-224 precursor (pre-miR-224) (Ambion, Foster City, CA, USA) using Lipofectamine 2000 (Invitrogen). $2 \times 10^{5}$ cells were seeded into each well of a 6-well plate and transfected for $24 \mathrm{~h}$ or $48 \mathrm{~h}$. Transfected cells were used in further assays or RNA/protein extraction.

\section{MTT assay}

$2 \times 10^{4}$ SW480 cells were plated onto 96-well plates for $24 \mathrm{~h}$. The cells were then transfected with $50 \mathrm{nM}$ premiR-224 or pre-miR-nc. At different time points ( $24 \mathrm{~h}$, $48 \mathrm{~h}$ and $72 \mathrm{~h}$ ), the culture medium was removed and replaced with culture medium containing $10 \mu \mathrm{l}$ of sterile MTT dye $(5 \mathrm{mg} / \mathrm{ml})$. After incubation at $37^{\circ} \mathrm{C}$ for $4 \mathrm{~h}$, the MTT solution was removed, and $150 \mu$ limethyl sulfoxide (DMSO) was added to each well followed by measuring the absorbance at $570 \mathrm{~nm}$ on an enzyme immunoassay analyzer (Bio-Rad).

\section{Migration and invasion assays}

For migration assays, $5 \times 10^{4}$ cells transfected with either premiR-224 or pre-miR-nc were placed into Boyden chambers (Corning, Cambridge, MA, USA) with an $8.0 \mathrm{~mm}$ pore membrane. For invasion assays, $5 \times 10^{4}$ cells were placed into chambers coated with $150 \mu \mathrm{g}$ of Matrigel (BD Biosciences, Bedford, MD, USA). Medium containing 10\% fetal bovine serum in the lower chamber served as the chemoattractant. After the cells were incubated for $48 \mathrm{~h}$ at $37^{\circ} \mathrm{C}$ in a humidified incubator with $5 \% \mathrm{CO}_{2}$, the cells remaining on the upper surface of the membranes were removed, whereas the cells adhering to the lower surface were fixed, stained with hematoxylin and counted under a microscope at a magnification of $400 \times$ to calculate their relative numbers.

\section{Western blot analysis}

Immunoblotting was performed to detect the expression of SMAD4 in CRC cell lines. Transfected cells were lysed in RIPA lysis buffer (ProMab Biotechnology). Protein 
was loaded onto a SDS-PAGE minigel and transferred onto PVDF membrane. After probed with 1:500 diluted mouse polyclonal SMAD4 antibody (Santa Cruz Biotechnology, Santa Cruz, CA, USA) at $4^{\circ} \mathrm{C}$ overnight, the blots were subsequently incubated with HRP-conjugated secondary antibody (1:5000). Signals were visualized using ECL Substrates (Millipore, MA, USA). GAPDH was used as an endogenous protein for normalization.

\section{Luciferase assay}

For luciferase reporter experiments, the wild-type and mutated 3'UTR of SMAD4 mRNA were subcloned into the XhoI and NotI site of the psicheck-2 vector (Promega) and the new vectors were named psicheck-2-SMAD4-WT and psicheck-2-SMAD4-MUT, respectively. The primers as shown in Table 1 were used to amplify specific fragments. For reporter assay, HEK 293T cells were plated onto 24-well plates at $2 \times 10^{4}$ cells/well and transfected with $200 \mathrm{ng}$ of psicheck-2-SMAD4-WT or psicheck2-SMAD4-MUT and $40 \mathrm{nM}$ pre-miR-224 or pre-miR-nc using Lipofectamine 2000 (Invitrogen). Firefly luciferase was used to normalize the Renilla luciferase. After transfection for $48 \mathrm{~h}$, cells were harvested and assayed with Dual-Luciferase Reporter Assay System (Promega) according to the manufacturer's protocols.

\section{Statistical analysis}

All data presented in this study have been repeated at least three times from three independent experiments.

Table 1 PCR primers and oligonucleotide sequences of constructs in luciferase reporter assay

\begin{tabular}{|c|c|c|c|}
\hline Targets & Type & Primers & Oligonucleotide sequence $\left(5^{\prime}-3^{\prime}\right)$ \\
\hline \multicolumn{4}{|l|}{ SMAD4 } \\
\hline \multirow[t]{2}{*}{ (site 1 , site 2 ) } & WT1 & Sense & $\begin{array}{l}\text { CACAACTCGAGAGGCACAAGGTT } \\
\text { GGTTGCTA }\end{array}$ \\
\hline & & Antisense & $\begin{array}{l}\text { GGAAAAAAGCGGCCGCGACCTTC } \\
\text { TGAGCAAGGCAGT }\end{array}$ \\
\hline SMAD4 & WT2 & Sense & $\begin{array}{l}\text { CACAACTCGAGTGTGTGACACCAC } \\
\text { CСTCCTA }\end{array}$ \\
\hline (site3) & & Antisense & $\begin{array}{l}\text { AAGGAAAAAAGCGGCCGCTCAATC } \\
\text { CAAGCCCGTGAGTC }\end{array}$ \\
\hline SMAD4 & MUT1 & Sense & $\begin{array}{l}\text { TGATGCACTGAATTITGGTATAATG } \\
\text { TITAAATCATGT }\end{array}$ \\
\hline (site1) & & Antisense & $\begin{array}{l}\text { CCAAAAATTCAGTGCATCAAATCAA } \\
\text { GTACAAAAATA }\end{array}$ \\
\hline SMAD4 & MUT2 & Sense & $\begin{array}{l}\text { TGGCACACTGAATGTATAGAGAATTT } \\
\text { AAGTAGAAAAGTT }\end{array}$ \\
\hline (site2) & & Antisense & $\begin{array}{l}\text { TATACATTCAGTGTGCCAATTGATAT } \\
\text { GATCATTGATGG }\end{array}$ \\
\hline SMAD & MUT3 & Sense & $\begin{array}{l}\text { GATTAACACTGAATGGCTGGATCATT } \\
\text { CAGAGCTCTCTTCT }\end{array}$ \\
\hline (site3) & & Antisense & $\begin{array}{l}\text { GCCATTCAGTGTTAATCAAAATGGAC } \\
\text { CTAAAAAGAGCCA }\end{array}$ \\
\hline
\end{tabular}

Continuous variables were expressed as the mean \pm standard deviation. Measurement data were analyzed using Student's $t$-test, while categorical data were studied using chi-square test. Receiver operating characteristic (ROC) curve was used to determine the cut off value of miR-224 expression. The postoperative survival rate was analyzed with Kaplan-Meier method, and differences in survival rates were assessed with log-rank test. All statistical analyses were performed using SPSS 16.0 software (SPSS, Chicago, IL, USA). Two-sided $P$-values were calculated, and differences were considered significant at $P$-values of $<0.05$.

\section{Results}

\section{Patients' characteristics}

A total of 108 patients were included in this study with 40 patients in relapse group (relapse within 3 years after radical surgery) and 68 patients in non-relapse group (no relapse within 3 years after radical surgery). There were no differences between the two groups in terms of age, gender, tumor location, differentiation and TNM stage. The details were seen in Table 2.

\section{Correlations between miR-224 expressions and disease relapse}

In this study, we found that miR-224 expression in tumor tissues was significantly higher than that in normal tissues $(P<0.01$, Figure $1 \mathrm{~A})$. Using the samples from the second cohort, we found that the miR-224 expression levels were significantly up-regulated in the tissues of CRC patients with disease relapse $(n=40)$ compared with those without disease relapse $(\mathrm{n}=68) \quad(P<0.01$,

Table 2 Clinicopathological characteristics of colorectal cancer patients

\begin{tabular}{lccc}
\hline & Relapse $(\mathbf{n}=\mathbf{4 0})$ & Nonrelapse $(\mathbf{n}=\mathbf{6 8})$ & $\boldsymbol{p}$-Value \\
\hline Age (years) & $66(35-82)$ & $66(31-81)$ & 0.576 \\
Gender & & & \\
$\quad$ Male & 24 & 47 & 0.335 \\
$\quad$ Female & 16 & 21 & \\
Location & & & 0.245 \\
$\quad$ Colon & 12 & 28 & \\
Rectum & 28 & 40 & \\
Differentiation & & & \\
$\quad$ Well, moderate & 22 & 44 & \\
Poor, mucinous & 18 & 24 & \\
TNM stage & & & \\
I & 5 & 51 & \\
॥ & 35 & 17 & \\
\hline
\end{tabular}

Well: well-differentiated adenocarcinoma,moderate: moderately differentiated adenocarcinoma, poor: poorly differentiated adenocarcinoma, mucinous: mucinous carcinoma. 


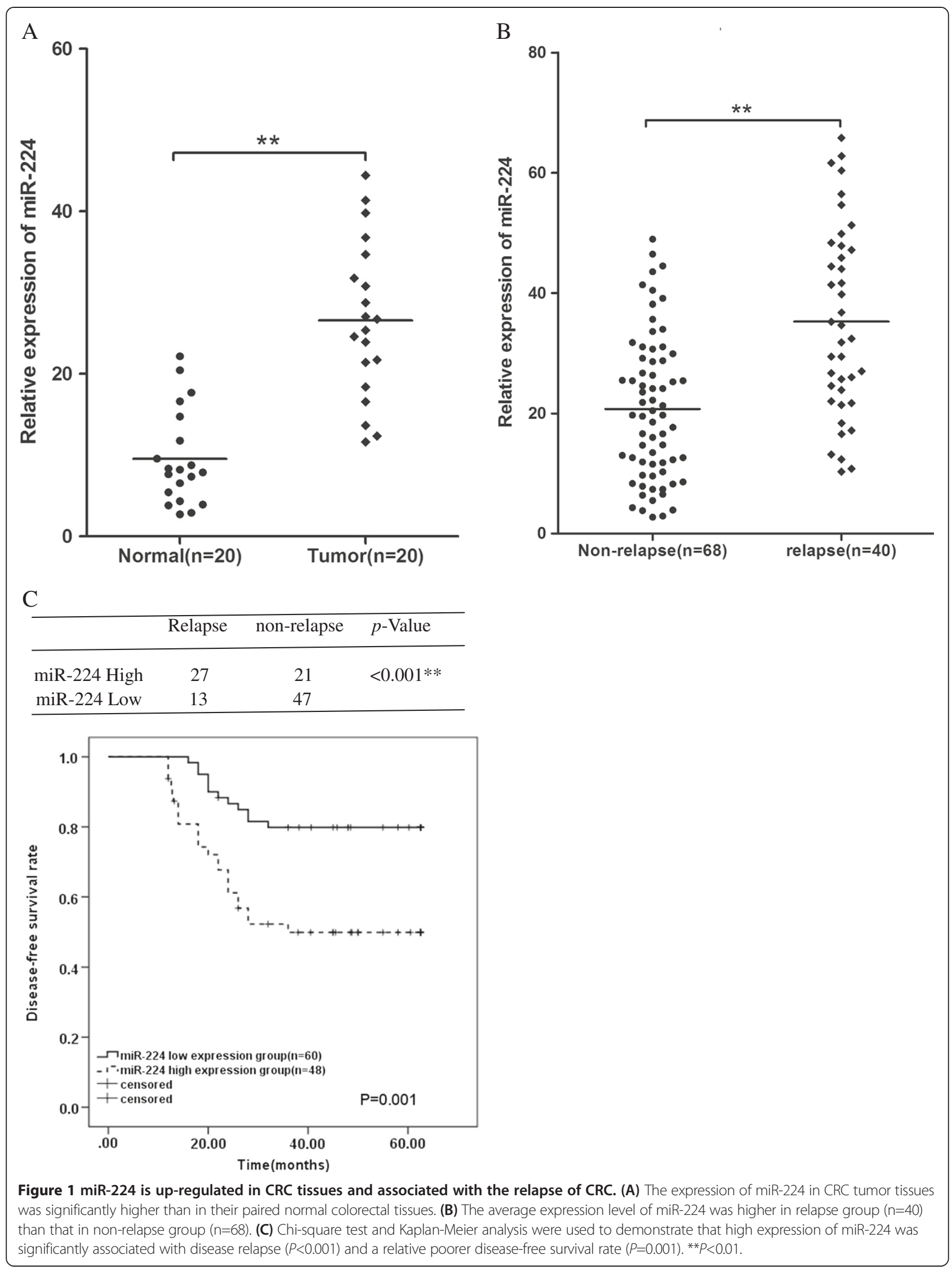


Figure 1B).The expression levels of the miR-224 were categorized as low or high in relation to the cutoff value (25.72) on the basis of ROC curve analysis. Therefore, 48 patients were included in the high expression group and 60 in the low-expression group. Among patients with miR-224 high expression, 27 patients relapsed (27/48, $56.3 \%)$, while only 13 patients relapsed (13/60, 21.7\%) among patients with miR-224 low expression. Using chi-square test and Kaplan-Meier analysis, the results demonstrated that high miR-224 expression was significantly associated with disease relapse and a relative poorer disease-free survival rate (Figure 1B).

\section{MiR-224 promotes CRC cell proliferation}

MiR-224 was upregulated in CRC, implicating its potential role in CRC cells biological properties. To further characterize the functional importance in CRC tumorigenesis, we examined the effect of miR-224 on the proliferation of CRC cells using MTT assay. Compared to pre-miR-nc, transfection with pre-miR-224 in SW480 cells led to an approximately 6-fold increase in miR-224 expression as detected by qRT-PCR (Figure 2A). We observed that overexpression of miR-224 significantly promoted the proliferation of SW480 cells, at 24, 48, $72 \mathrm{~h}$ after transfection $(P<0.05$, Figure $2 \mathrm{~B})$.

\section{MiR-224 regulates CRC cell invasion and migration in vitro}

The potential roles of miR-224 in CRC cell migration and invasion were assessed using transwell migration and invasion assays. We observed that cell migration was significantly increased following transfection with pre-miR-224 compared with the negative control $(P<0.01$, Figure $3 \mathrm{~A}$, $3 B)$. We then examined the effect of miR-224 on cell invasion across an extracellular matrix and showed that in SW480 cells, the overexpression of miR-224 markedly enhanced the invasive potential compared with the control $(P<0.05$, Figure $3 \mathrm{~A}, 3 \mathrm{~B})$. These observations suggest that miR-224 plays an important role in promoting migration and invasive ability of CRC cells.

\section{MiR-224 binds to the 3'UTR of SMAD4}

Analysis by using publicly available programs, TargetScan (http://www.targetscan.org/) and miRanda (http://www. microrna.org/microrna/home.do), indicates that SMAD4 is theoretically the target gene of miR-224 (Figure 4A). Therefore, in the current study, we further determined whether SMAD4 gene was an authentic target gene of miR-224 in CRC.

We performed a luciferase reporter assay to verify that miR-224 directly targets SMAD4.Sequences of the 3' UTR of the SMAD4 mRNA surrounding the two close miR-224 potential binding sites (site 1 and site 2 ) containing the wild-type (WT1).we cloned the regions of 3'UTR each containing one putative miR-224 binding site into the psicheck-2 vector and named as WT1 (site1, site2) and WT2 (site3) (Figure 4A). The reporter constructs harboring mutation of the miR-224 target sites were generated similarly (MUT1, MUT2 and MUT3) (Figure 4A). The luciferase reporter constructs were transfected into HEK 293 T cells, along with pre-miR-224 or pre-miR-nc. Luciferase activites were then measured. The luciferase activity of WT1 (site1, site2) reporter transfected with pre-miR-224 was significantly decreased compared with control $(P<0.01$, Figure 4B), while the luciferase activity of the WT2 (site3) reporter was not interfered with after transfection with pre-miR-224 compared with control ( $P>0.05$, Figure $4 \mathrm{~B})$. These data indicate that miR-224 may target SMAD4 gene through the seeding region of wild type 3'UTR (site1, site2). However, the luciferase reporter activity was not inhibited by miR-224 when the seeding sites were mutated.
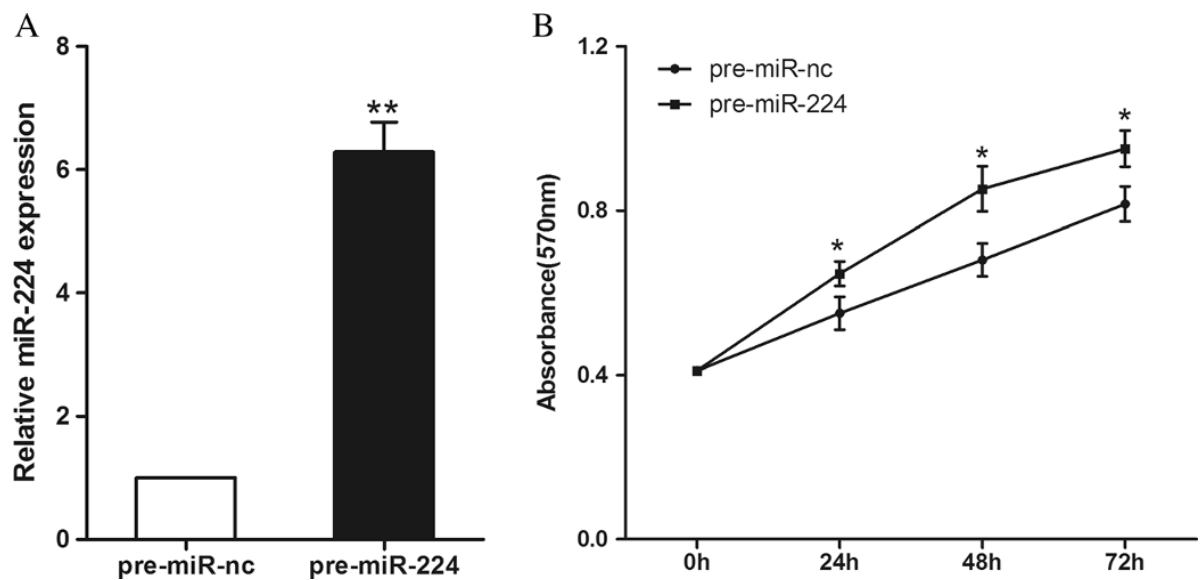

Figure 2 MiR-224 promotes CRC cell proliferation. (A) miR-224 expression in SW480 cells transfected with pre-miR-224 or pre-miR-nc. (B) MTT assay was performed to determine SW480 proliferation. ${ }^{*} P<0.05$. ${ }^{*} P<0.01$. 


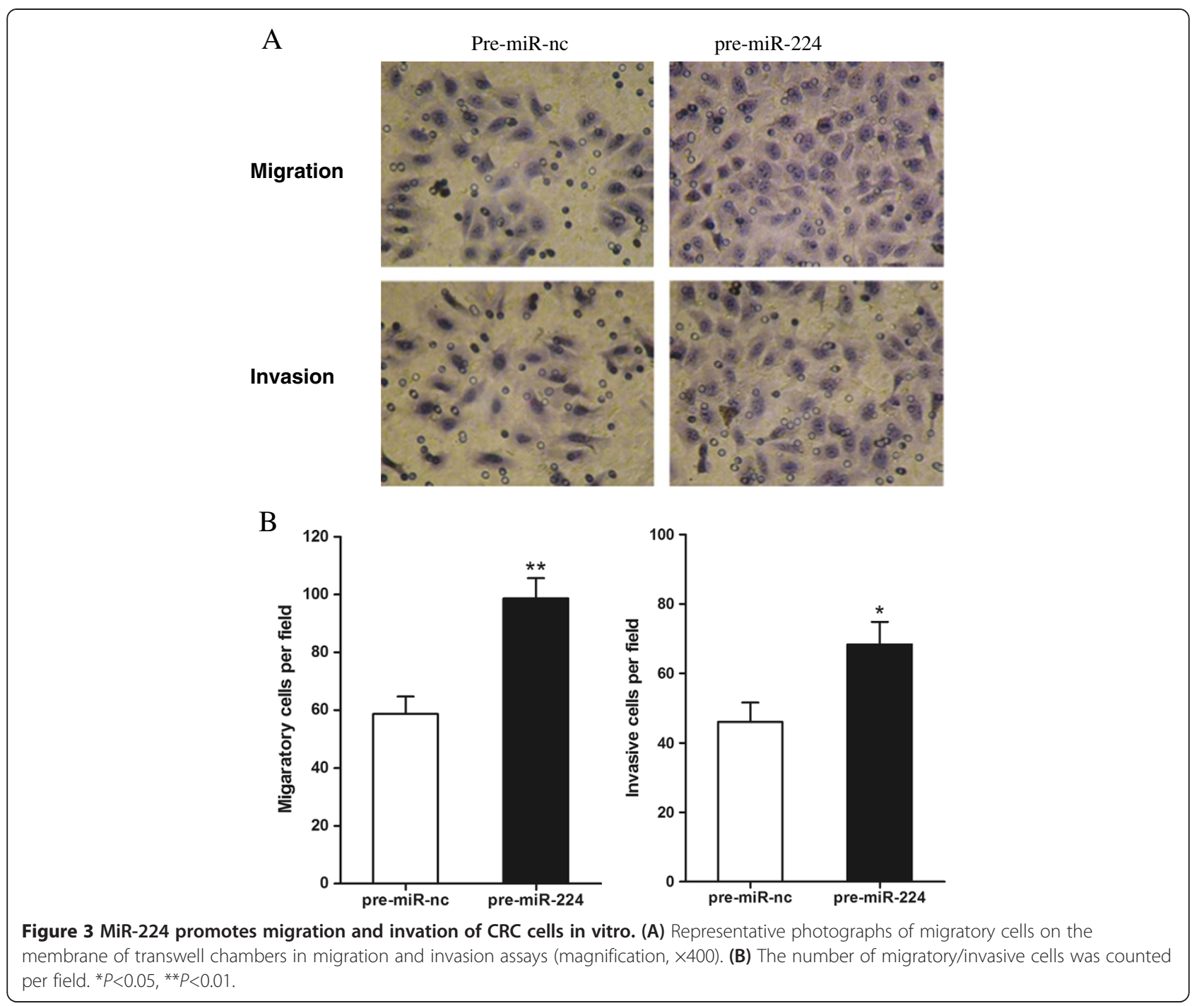

\section{MiR-224 inhibits SMAD4 protein expression but not mRNA level}

To further confirm that SMAD4 was the downstream target of miR-224, we analyzed SMAD4 mRNA and protein levels in transfected SW480 cells by qRT-PCR and Western blot. Western blot analysis demonstrated that high expression of miR-224 dramatically suppressed the endogenous protein level of SMAD4 $(P<0.01$, Figure 5B), while mRNA remained unchanged $(P>0.05$, Figure $5 A)$. Thus, SMAD4 is likely to be suppressed by miR-224 through translational inhibition.

\section{Disscussion}

It was reported that disease relapse was an important factor leading to the poor survival of colorectal cancer patients [17]. At present, poor clinicopathological characteristics and high carcinoembryonic antigen (CEA) level were known as high risk factors for relapse but with varying reliability reported [18]. Therefore, effective biomarkers were wanted to distinguish between patients with and without high relapse risk followed by appropriate therapy in CRC.

Differential miRNA expression in tumor samples compared to normal samples or between groups of tumor samples with a favourable and poor clinical outcome have been used to generate miRNA signatures with potential prognostic and/or predictive value $[19,20]$. In the current study, we confirmed that miR-224 expression in CRC tumor tissues was significantly higher than that in normal tissues. Furthermore, miR-224 expression levels were significantly up-regulated in the tissues of CRC patients with disease relapse compared with those without disease relapse, and the CRC patients with up-regulated miR-224 in tumor tissues had a high risk of relapse. Thus, miR-224 could function as a potential predictive marker for relapse following radical surgery of colorectal cancer. 


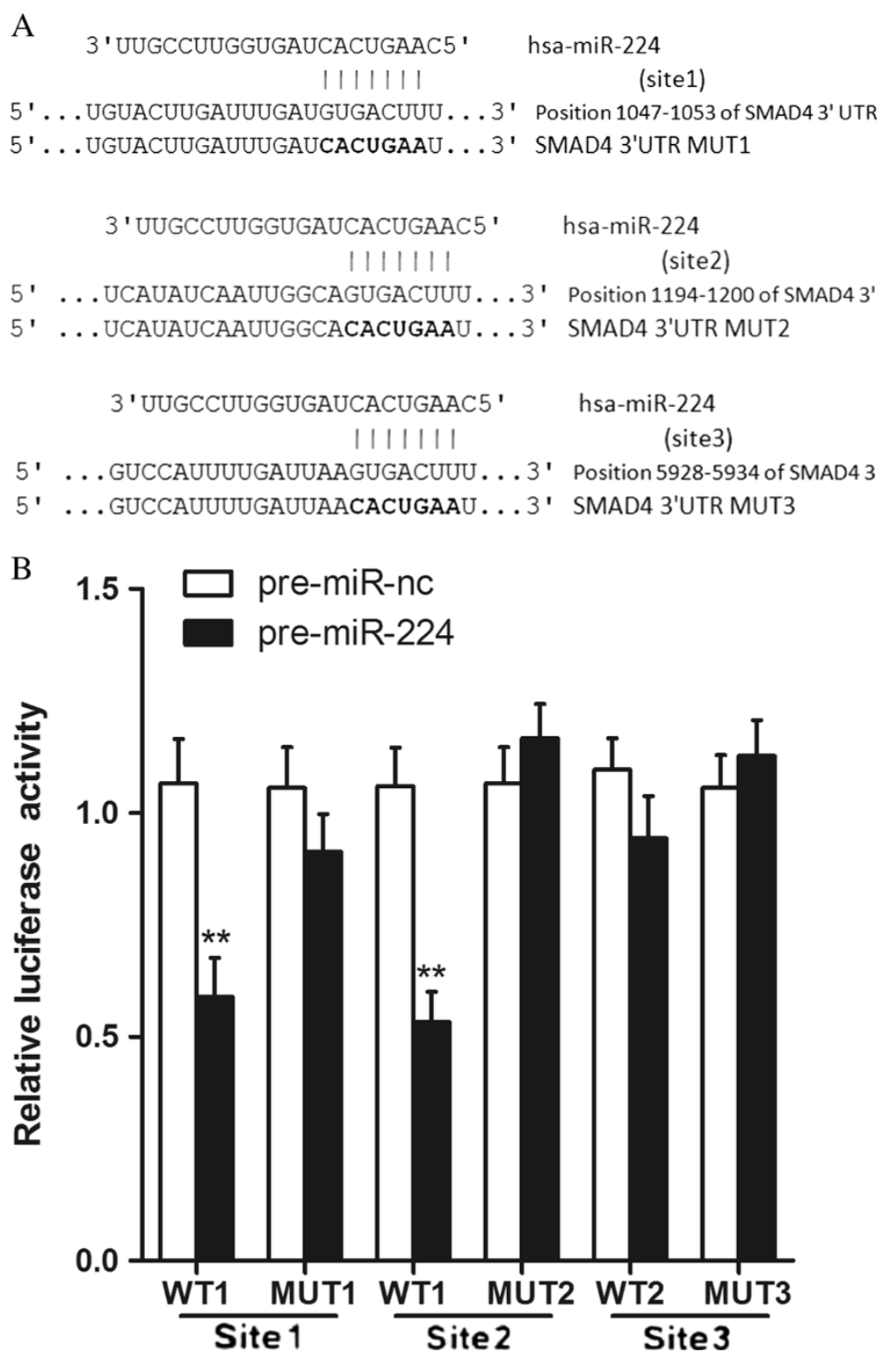

Figure 4 SMAD4 is a validated target of miR-224. (A) The wild-type and mutated 3'UTR of SMAD4, with the seed region (site1, site2 and site3) and base substitutions (bold). (B) Dual luciferase report assays were performed on HEK 293T cells. Each bar represents mean values \pm SD from three independent experiments. ${ }^{*} P<0.01$.

In this study, we investigated the biological role of miR-224 in regulating CRC cancer progression. Our results revealed that miR-224 promoted CRC cells growth, migration and invasion in vitro. To address the molecular mechanisms involved in miR-224-mediated changes of biological properties, SMAD4 was selected for further study because it was predicted to be a target of miR-224 by bioinformatics analysis. SMAD4 belongs to the evolutionarily conserved family of SMAD proteins which are transmitters of signals from the transforming growth factor- $\beta$ (TGF- $\beta$ ) superfamily of cytokines [21]. It is suggested that SMAD4 can function as a tumor suppressor gene in gastrointestinal carcinoma $[22,23]$. Previous study showed that patients with tumors expressing low SMAD4 levels had significantly worse overall and disease-free survival than patients with high levels in colorectal cancer [24]. Moreover, Loss of SMAD4 expression was found to be associated with liver metastasis, and reduced SMAD4 expression enhances tumorigenicity in CRC [25]. A recent study also reported that loss of SMAD4 promoted migration and invasion, and mediated epithelial- 
$\overline{\mathrm{A}}$

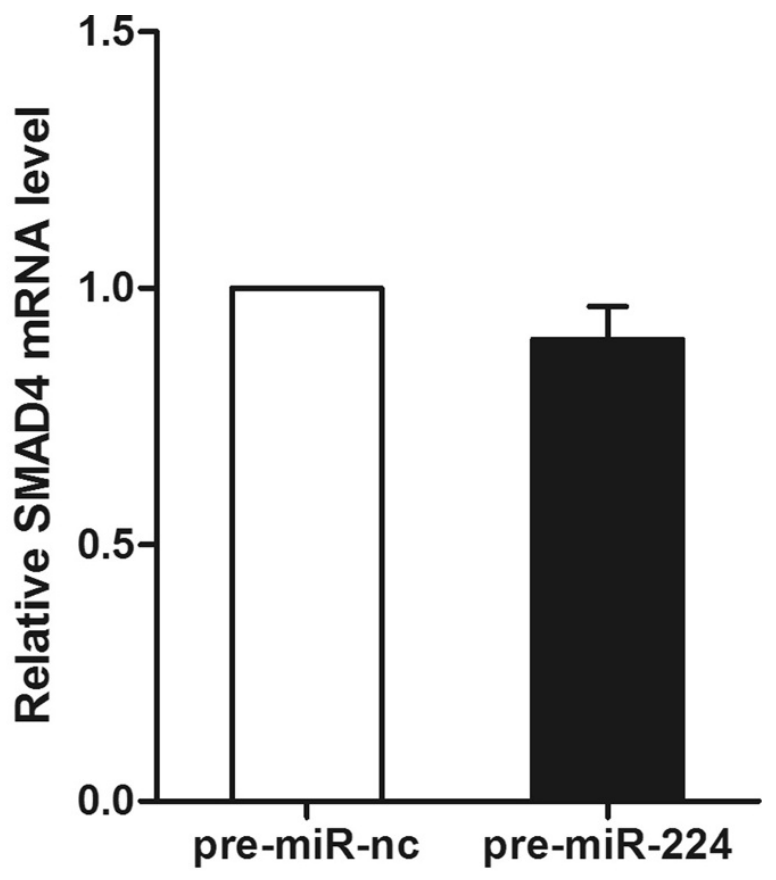

B
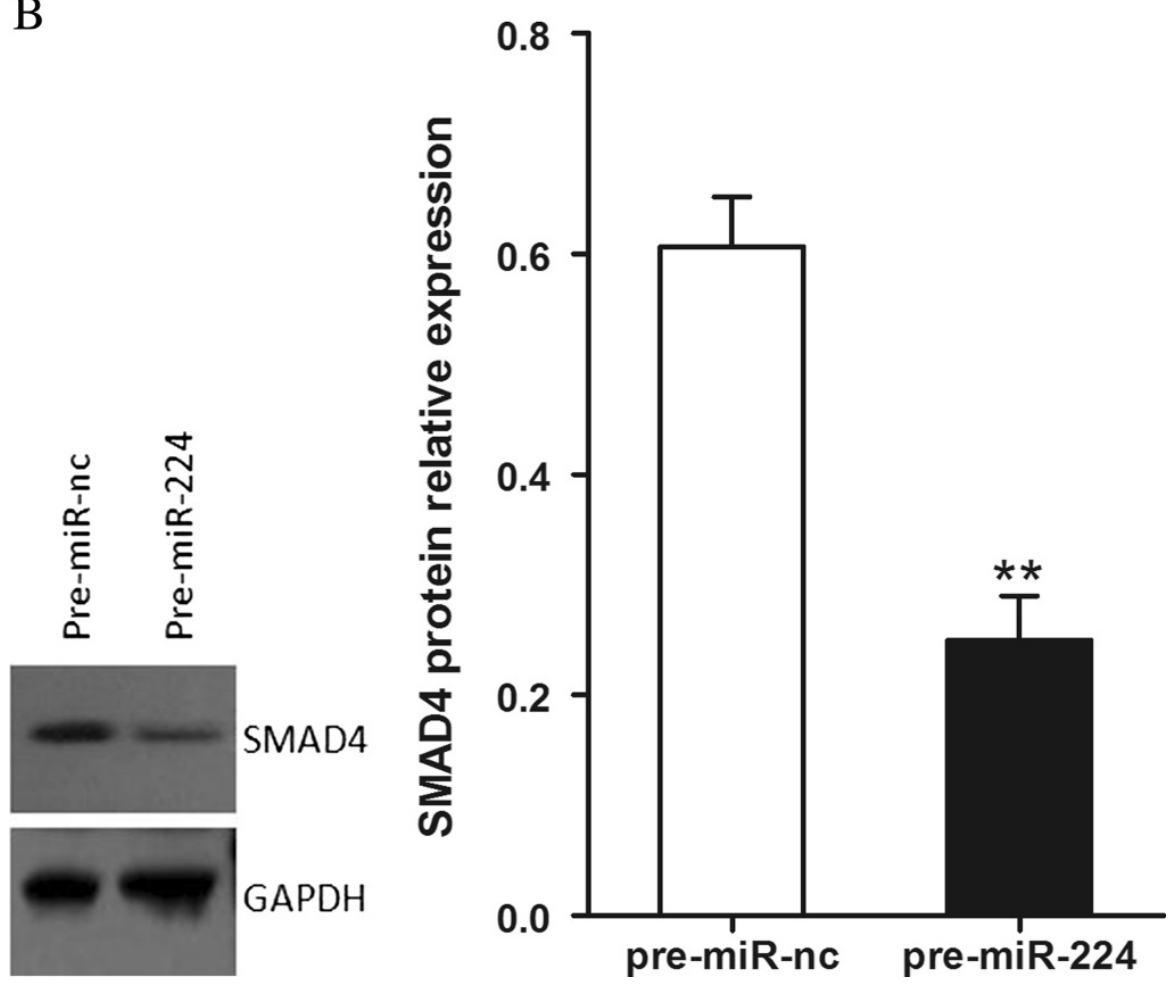

Figure 5 MiR-224 down-regulates SMAD4 protein expression but not mRNA level. (A) The expression of SMAD4 mRNA was analyzed by qRT-PCR assay. (B) The expression of SMAD4 protein was analyzed by western blot assay. ${ }^{* *} P<0.01$.

mesenchymal transition (EMT) in CRC cell line SW480 $[26,27]$. Hence, it is an attractive target for anti-cancer therapy in colorectal cancer.

Our study suggested that SMAD4 was a possible target of miR-224. Firstly, the luciferase reporter assay demonstrated its down-regulation was mediated by the direct binding of miR-224 to the SMAD4 3'-UTR, because the alteration of this region abolished this effect. Secondly, over-expression of miR-224 suppressed SMAD4 protein levels without any change in SMAD4 mRNA expression. 
Therefore, we proposed that the main mechanism of miR224-induced SMAD4 suppression was post-transcriptional. In addition, SMAD4 has been confirmed as a target gene of miR-224 in Granulosa Cells [28]. In our study, restoration of miR-224 promoted CRC cell proliferation, migration and invasion, this could possibly be due to miR-224mediated down-regulation of SMAD4 expression.

Cancer stem cells (CSCs) are predicted to be critical drivers of tumor progression due to CSC characteristics including self-renewal and pluripotency, drug resistance, limitless proliferative potential and metastatic capability, suggesting that targeting CSC characteristics would likely eliminate CSCs which are the "seeds" of tumor recurrence and metastasis. Specific miRNAs have been shown to be involved in CSC regulation in CRC, such as miR-328 and miR-449b [29,30]. Recently, Fellenberg et al. showed that the miR-224 functions as an important regulator of stem cells induction by targeting the apoptosis inhibitor, API5 [31]. The generation of CSCs involves a process of mesenchymal-to-epithelial transition (MET), therefore factors inducing MET or blocking the EMT by inhibiting TGF- $\beta$ signaling play an essential role in cell reprogramming [32]. It is also known that TGF$\beta /$ Smad4 signaling plays a crucial role in the regulation of EMT as well as cell stemness in CRC [27,33]. We have discovered a novel target of miR-224 (Smad4), which has key function in TGF- $\beta$ signaling, providing the possibility that miR-224 may mediate CSC by suppressing TGF$\beta /$ Smad4 activity. Thus, our studies might provide a potential molecular mechanism and crosstalk of CSC regulation and tumor metastasis.

In summary, the association between increased levels of miR-224 and disease relapse in CRC patients indicated that miR-224 was a potential biomarker for identifying high-risk CRC patients after radical resection. The present data showed that miR-224 had oncogenic effects, including the promotion of CRC cell proliferation, migration and invasion, at least in part by targeting the anti-oncogene SMAD4, highlighting the function of miR-224 in the process of tumor progression.

Competing interests

The authors declare that they have no competing interests.

\section{Authors' contributions}

ZGJ, XHX and LY performed experiments; ZGJ, ZH and ZT designed research and wrote the paper; $\mathrm{ZGJ}$ and $\mathrm{ZH}$ analyzed data. All authors read and approved the final manuscript.

\section{Acknowledgments}

This study was supported by Scientific Research Fund of Sichuan Provincial Education Department of China (CBY12-A-ZD16).

\section{Author details}

${ }^{1}$ The First Department of General Surgery, The Affiliated Hospital of North Sichuan Medical College, Nanchong, Sichuan, People's Republic of China. ${ }^{2}$ Institute of Hepatobiliary, Pancreas and Intestinal Disease, North Sichuan Medical College, Nanchong, Sichuan, People's Republic of China.
${ }^{3}$ Department of Pathology, The North Sichuan Medical College, Nanchong, Sichuan, People's Republic of China. ${ }^{4}$ Department of Microbiology and Parasitology, North Sichuan Medical College, Nanchong, Sichuan, People's Republic of China.

Received: 10 July 2013 Accepted: 20 October 2013

Published: 23 October 2013

\section{References}

1. Jemal A, Siegel R, Ward E, Hao Y, Xu J, Murray T, Thun MJ: Cancer statistics, 2008. CA Cancer J Clin 2008, 58(2):71-96.

2. Kobayashi H, Mochizuki H, Sugihara K, Morita T, Kotake K, Teramoto T, Kameoka S, Saito Y, Takahashi K, Hase K, et al: Characteristics of recurrence and surveillance tools after curative resection for colorectal cancer: a multicenter study. Surgery 2007, 141(1):67-75.

3. Bartel DP: MicroRNAs: genomics, biogenesis, mechanism, and function. Cell 2004, 116(2):281-297.

4. Bartel DP: MicroRNAs: target recognition and regulatory functions. Cell 2009, 136(2):215-233.

5. Munker R, Calin GA: MicroRNA profiling in cancer. Clin Sci (Lond) 2011, 121(4):141-158.

6. Farazi TA, Spitzer J, Morozov $P$, Tuschl T: miRNAs in human cancer. J Pathol 2011, 223(2):102-115.

7. Lee DY, Deng Z, Wang CH, Yang BB: MicroRNA-378 promotes cell survival, tumor growth, and angiogenesis by targeting SuFu and Fus-1 expression. Proc Natl Acad Sci USA 2007, 104(51):20350-20355.

8. Paterson EL, Kazenwadel J, Bert AG, Khew-Goodall Y, Ruszkiewicz A, Goodall GJ: Down-regulation of the miRNA-200 family at the invasive front of colorectal cancers with degraded basement membrane indicates EMT is involved in cancer progression. Neoplasia 2013, 15(2):180-191.

9. Zhang GJ, Xiao HX, Tian HP, Liu ZL, Xia SS, Zhou T: Upregulation of microRNA-155 promotes the migration and invasion of colorectal cancer cells through the regulation of claudin-1 expression. Int J Mol Med 2013, 31(6):1375-1380.

10. Shen $S N$, Wang LF, Jia YF, Hao YQ, Zhang L, Wang H: Upregulation of microRNA-224 is associated with aggressive progression and poor prognosis in human cervical cancer. Diagn Pathol 2013, 8:69.

11. Mees ST, Mardin WA, Sielker S, Willscher E, Senninger N, Schleicher C, Colombo-Benkmann M, Haier J: Involvement of CD40 targeting miR-224 and miR-486 on the progression of pancreatic ductal adenocarcinomas. Ann Surg Oncol 2009, 16(8):2339-2350.

12. Huang L, Dai T, Lin X, Zhao X, Chen X, Wang C, Li X, Shen H, Wang X: MicroRNA-224 targets RKIP to control cell invasion and expression of metastasis genes in human breast cancer cells. Biochem Biophys Res Commun 2012, 425(2):127-133.

13. Zhang Y, Takahashi S, Tasaka A, Yoshima T, Ochi H, Chayama K: Involvement of microRNA-224 in cell proliferation, migration, invasion, and anti-apoptosis in hepatocellular carcinoma. J Gastroenterol Hepatol 2013, 28(3):565-575.

14. Motoyama K, Inoue H, Takatsuno Y, Tanaka F, Mimori K, Uetake H, Sugihara K, Mori M: Over- and under-expressed microRNAs in human colorectal cancer. Int J Oncol 2009, 34(4):1069-1075.

15. Arndt GM, Dossey L, Cullen LM, Lai A, Druker R, Eisbacher M, Zhang C, Tran N, Fan $\mathrm{H}$, Retzlaff $\mathrm{K}$, et al: Characterization of global microRNA expression reveals oncogenic potential of miR-145 in metastatic colorectal cancer. BMC cancer 2009, 9:374.

16. Mencia N, Selga E, Noe V, Ciudad CJ: Underexpression of miR-224 in methotrexate resistant human colon cancer cells. Biochem Pharmacol 2011, 82(11):1572-1582.

17. Li S, Gao J, Gu J, Yuan J, Hua D, Shen L: MicroRNA-215 inhibits relapse of colorectal cancer patients following radical surgery. Medical oncology 2013, 30(2):549.

18. Tsai HL, Chu KS, Huang YH, Su YC, Wu JY, Kuo CH, Chen CW, Wang JY Predictive factors of early relapse in UICC stage I-III colorectal cancer patients after curative resection. J Surg Oncol 2009, 100(8):736-743.

19. Garzon R, Marcucci G: Potential of microRNAs for cancer diagnostics, prognostication and therapy. Curr Opin Oncol 2012, 24(6):655-659.

20. Albulescu R, Neagu M, Albulescu L, Tanase C: Tissular and soluble miRNAs for diagnostic and therapy improvement in digestive tract cancers. Expert Rev Mol Diagn 2011, 11(1):101-120. 
21. Massague J, Chen YG: Controlling TGF-beta signaling. Genes Dev 2000, 14(6):627-644

22. Wang LH, Kim SH, Lee JH, Choi YL, Kim YC, Park TS, Hong YC, Wu CF, Shin YK: Inactivation of SMAD4 tumor suppressor gene during gastric carcinoma progression. Clin Cancer Res 2007, 13(1):102-110.

23. Maitra A, Molberg K, Albores-Saavedra J, Lindberg G: Loss of Dpc4 expression in colonic adenocarcinomas correlates with the presence of metastatic disease. Am J Pathol 2000, 157(4):1105-1111.

24. Alazzouzi H, Alhopuro P, Salovaara R, Sammalkorpi H, Jarvinen H, Mecklin JP, Hemminki A, Schwartz S Jr, Aaltonen LA, Arango D: SMAD4 as a prognostic marker in colorectal cancer. Clin Cancer Res 2005, 11(7):2606-2611.

25. Zhang B, Halder SK, Kashikar ND, Cho YJ, Datta A, Gorden DL, Datta PK: Antimetastatic role of Smad4 signaling in colorectal cancer. Gastroenterology 2010, 138(3):969-980. e961-963.

26. Muller N, Reinacher-Schick A, Baldus S, van Hengel J, Berx G, Baar A, van Roy F, Schmiegel W, Schwarte-Waldhoff I: Smad4 induces the tumor suppressor Ecadherin and P-cadherin in colon carcinoma cells. Oncogene 2002, 21 (39):6049-6058.

27. Pohl M, Radacz Y, Pawlik N, Schoeneck A, Baldus SE, Munding J, Schmiegel W, Schwarte-Waldhoff I, Reinacher-Schick A: SMAD4 mediates mesenchymalepithelial reversion in SW480 colon carcinoma cells. Anticancer Res 2010, 30(7):2603-2613.

28. Yao G, Yin M, Lian J, Tian H, Liu L, Li X, Sun F: MicroRNA-224 is involved in transforming growth factor-beta-mediated mouse granulosa cell proliferation and granulosa cell function by targeting Smad4. Mol Endocrinol 2010, 24(3):540-551.

29. Xu XT, Xu Q, Tong JL, Zhu MM, Nie F, Chen X, Xiao SD, Ran ZH: MicroRNA expression profiling identifies miR-328 regulates cancer stem cell-like SP cells in colorectal cancer. Br J Cancer 2012, 106(7):1320-1330.

30. Fang Y, Gu X, Li Z, Xiang J, Chen Z: miR-449b inhibits the proliferation of SW1116 colon cancer stem cells through downregulation of CCND1 andE2F3 expression. Oncol Rep 2013, 30(1):399-406.

31. Fellenberg J, Saehr H, Lehner B, Depeweg D: A microRNA signature differentiates between giant cell tumor derived neoplastic stromal cells and mesenchymal stem cells. Cancer Lett 2012, 321(2):162-168.

32. Li R, Liang J, Ni S, Zhou T, Qing X, Li H, He W, Chen J, Li F, Zhuang Q, et al: A mesenchymal-to-epithelial transition initiates and is required for the nuclear reprogramming of mouse fibroblasts. Cell Stem Cell 2010, 7(1):51-63.

33. Roy S, Majumdar AP: Signaling in colon cancer stem cells. J Mol Signal 2012, 7(1):11.

doi:10.1186/1475-2867-13-104

Cite this article as: Zhang et al.: Up-regulation of miR-224 promotes cancer cell proliferation and invasion and predicts relapse of colorectal cancer. Cancer Cell International 2013 13:104

\section{Submit your next manuscript to BioMed Central and take full advantage of:}

- Convenient online submission

- Thorough peer review

- No space constraints or color figure charges

- Immediate publication on acceptance

- Inclusion in PubMed, CAS, Scopus and Google Scholar

- Research which is freely available for redistribution 